\title{
Total arch repair with frozen elephant trunk for type A acute aortic dissection: the "zone 0 arch repair" strategy
}

\author{
Hiroshi Yamamoto, Takayuki Kadohama, Daichi Takagi \\ Department of Cardiovascular Surgery, Akita University Graduate School of Medicine, Akita, Japan \\ Correspondence to: Hiroshi Yamamoto. Department of Cardiovascular Surgery, Akita University Graduate School of Medicine, Hondo 1-1-1, Akita, \\ Akita 010-8543, Japan. Email: h-yama@cvs.med.akita-u.ac.jp.
}

Submitted Nov 26, 2019. Accepted for publication Feb 17, 2020.

doi: $10.21037 /$ acs.2020.02.16

View this article at: http://dx.doi.org/10.21037/acs.2020.02.16

\section{Introduction}

According to a conventional "tear-oriented aortic resection" strategy, ascending aortic or hemi-arch replacement (HAR) is recommended if the primary tear is in the ascending aorta, while total arch replacement (TAR) is recommended if it is in, or more distal to the arch. This strategy has resulted in a trade-off between the two procedures, given that HAR is less invasive but risks late post-operative events, while TAR is more invasive but has a lower risk of late postoperative events. We developed the "zone 0 arch repair" strategy for type A acute aortic dissection, which is less invasive and carries less risk of requiring re-operation (1). It consists of frozen elephant trunk (FET) deployment from the zone 0 aorta into the descending aorta, ascending aortic replacement, and arch vessel reconstruction. Our strategy may have beneficial effects in post-operative mortality and in late aortic events. Here, we report the case of a patient with type A dissection, who underwent total arch repair using our strategy.

\section{Clinical vignette}

An 83-year-old woman, who presented with sudden chest pain and loss of consciousness and was diagnosed with type A aortic dissection by computed tomography (CT) scanning, was referred to our hospital for surgery. The CT scan revealed type A aortic dissection with a patent false lumen in the ascending aorta and aortic arch, but no dissection in the arch vessels. The echocardiogram showed cardiac tamponade but no aortic valve insufficiency.

\section{Surgical techniques}

\section{Preparation and exposition}

Surgical techniques based on our strategy have been described in the previous paper (1). Under general anesthesia and intra-tracheal intubation in a supine position, a 9-mm straight woven polyester graft (J Graft SHIELD $\mathrm{NEO}^{\circledR}$, Japan Lifeline; Tokyo, Japan) was anastomosed to the left axillary artery for systemic perfusion (used for arch vessel reconstruction). A median sternotomy was then carried out, which was followed by venous cannulation via the superior and inferior vena cava. Subsequently, hypothermic total cardiopulmonary bypass $(\mathrm{CPB})$ was initiated.

\section{Operation}

Cold blood cardioplegia was infused in a retrograde and antegrade manner after applying an aortic cross clamp (AXC). During systemic cooling, the proximal aortic end was cut $10-15 \mathrm{~mm}$ distal to the sinotubular junction. Surgical glue (Bioglue ${ }^{\circledR}$, CryoLife; Kennesaw, GA, USA) was applied into the false lumen to re-approximate the dissecting aortic walls, 3 staying stitches were placed just above the commissures, after which a continuous stitch of 5-0 polypropylene sutures (KIZUNA ${ }^{\circledR}$, Kono Seisakusho; Ichikawa, Japan) was placed, then reinforced with pericardial strips (Edwards Bovine Pericardial Patch ${ }^{\circledR}$, Edwards Lifesciences; Irvine, CA, USA) both inside and outside the aortic wall.

Systemic circulation via the left axillary artery was 
arrested at a rectal temperature lower than $25^{\circ} \mathrm{C}$, after which the left subclavian artery was ligated near its branching with a silk suture, then left axillary artery perfusion was resumed for left upper limb and left vertebrate artery circulation. Subsequently, the left carotid and brachiocephalic arteries were selectively perfused. The left carotid and brachiocephalic arteries on the arch side were closed, and the distal aortic end was transected 15-20 $\mathrm{mm}$ proximal to the branching of the brachiocephalic artery. An FET graft $(35 \mathrm{~mm}$ in diameter and $120 \mathrm{~mm}$ in stent length; J Graft FROZENIX ${ }^{\circledR}$, Japan Lifeline) was inserted from the distal aortic end (zone 0 ) into the descending aorta. The distal end of the FET graft was placed just proximal to the level of the aortic valve under transesophageal echocardiography. The FET graft diameter was determined according to pre-operative enhanced CT (90-100\% of the descending aortic diameter at the level of the main pulmonary arteries). The proximal nonstented cuff of the FET graft, cut approximately $3 \mathrm{~cm}$ above the distal aortic end, was anastomosed together with the distal aortic wall to a 4-branched woven polyester arch graft (J Graft SHIELD ${ }^{\circledR}$, Japan Lifeline) by a continuous stitch, using a 4-0 SH polypropylene suture. A $28-\mathrm{mm}$ diameter 4-branched arch graft was chosen according to the diameter of the repaired proximal aortic end. Distal perfusion was then recommended via the perfusion branch of the 4-branched arch graft (distal circulatory arrest time: $40 \mathrm{~min}$ ). During systemic rewarming, the arch graft was anastomosed to the repaired proximal aortic end by a continuous stitch using a 4-0 SH polypropylene suture (Prolene $^{\circledR}$, Ethicon; Somerville, NJ, USA). The AXC was then released for myocardial reperfusion (AXC time: $107 \mathrm{~min}$ ) after de-airing from the first branch of the arch graft. The third and second branches of the arch graft were anastomosed to the left carotid and brachiocephalic arteries, respectively (selective cerebral perfusion time: $102 \mathrm{~min}$ ). After CPB was stopped (CPB time: $182 \mathrm{~min}$ ), the first branch was connected to the graft for axillary artery reperfusion.

\section{Comments}

TAR has been reported to have a greater risk of postoperative complications than HAR (2). However, the incidence of late post-operative aortic events has been shown to be significantly lower in TAR than in HAR in acute DeBakey type I patients (3). Compared to the tear-oriented resection strategy for acute type A aortic dissection, the "zone 0 arch repair" strategy may lead to a more reasonable resolution in terms of minimizing surgical invasiveness and the incidence of late aortic reinterventions.

\section{Clinical results}

We have reported the clinical results of the "zone 0 arch repair" strategy for acute type A aortic dissection (1). In our previous study (108 patients; October 2014 through April 2018), the 30-day mortality rate and inhospital mortality rate were $2.8 \%$ (3 patients) and $6.5 \%$ (7 patients), respectively. There were no patients with newonset paraplegia. The overall survival rates were $89.8 \%$, $88.1 \%$, and $88.1 \%$ at 1,2 , and 3 years, respectively. The cumulative incidences of distal aortic re-intervention were $5.8 \%, 9.1 \%$, and $9.1 \%$ at 1,2 , and 3 years, respectively. Reinterventions for aortic events were performed in 7 patients during hospitalization (thoracic endovascular aortic repair in 5; Bentall operation in 1; intestinal resection in 1) and in 2 patients after discharge (thoracic endovascular aortic repair).

\section{Advantages}

We believe that a less invasive procedure such as HAR should be chosen for improved early post-operative results, even for patients with a primary tear in the aortic arch. Indeed in DeBakey type I patients with a primary tear in the ascending aorta, aortic dissection in the downstream aorta should be eliminated for better late post-operative results. The patent false lumen in aortic dissection is known to be accompanied by multiple tears (4). The FET technique can effectively eliminate the multiple tears located in the aortic arch and the proximal descending aorta during the initial surgery.

Arch vessel reconstruction, required in our strategy, does not seem to increase the risk of developing intra-operative stroke, as a multicenter study investigating risks of selective cerebral perfusion has demonstrated that the duration of cerebral perfusion has no influence on neurological outcomes (5).

\section{Caveats}

Our strategy has a potential risk of narrow working space for re-operation on the proximal anastomosis or aortic root, because the branches for arch vessel reconstruction are located in zone 0 and the AXC needs to be placed close 
to the proximal re-operation site. In our strategy, to avoid such a narrow working space for proximal re-operations, the first branch is used in reconstructing the left axillary artery, which will then enable the AXC to be placed between the first and second branches without compromising brachiocephalic artery perfusion.

\section{Acknowledgments}

None.

\section{Footnote}

Conflicts of Interest: The authors have no conflicts of interest to declare.

Open Access Statement: This is an Open Access article distributed in accordance with the Creative Commons Attribution-NonCommercial-NoDerivs 4.0 International License (CC BY-NC-ND 4.0), which permits the noncommercial replication and distribution of the article with the strict proviso that no changes or edits are made and the original work is properly cited (including links to both the formal publication through the relevant DOI and the license). See: https://creativecommons.org/licenses/by-nc$\mathrm{nd} / 4.0 /$.

\section{References}

1. Yamamoto H, Kadohama T, Yamaura G, et al. Total arch repair with frozen elephant trunk using the "zone 0 arch repair" strategy for type A acute aortic dissection. J Thorac Cardiovasc Surg 2019;159:36-45.

2. Kim JB, Chung CH, Moon DH, et al. Total arch repair versus hemiarch repair in the management of acute DeBakey type I aortic dissection. Eur J Cardiothorac Surg 2011;40:881-7.

3. Omura A, Miyahara S, Yamanaka K, et al. Early and late outcomes of repaired acute DeBakey type I aortic dissection after graft replacement. J Thorac Cardiovasc Surg 2016;151:341-8.

4. Tolenaar JL, van Keulen JW, Trimarchi S, et al. Number of entry tears is associated with aortic growth in type B dissections. Ann Thorac Surg 2013;96:39-42.

5. Di Eusanio M, Schepens MA, Morshuis WJ, et al. Brain protection using antegrade selective cerebral perfusion: A multicenter study. Ann Thorac Surg 2003;76:1181-8; discussion 1188-9.
Cite this article as: Yamamoto $\mathrm{H}$, Kadohama T, Takagi D. Total arch repair with frozen elephant trunk for type A acute aortic dissection: the "zone 0 arch repair" strategy. Ann Cardiothorac Surg 2020;9(3):251-253. doi: 10.21037/ acs.2020.02.16 